\title{
Normal Variants of the Lower Limbs in Pediatric Orthopedics
}

\author{
Stanley Jones, Sumukh Khandekar, Emmanuel Tolessa
}

Department of Orthopedics, Al Ahli Hospital, Doha, State of Qatar.

Email: stanjones80@hotmail.com

Received June $3^{\text {rd }}$, 2013; revised June $30^{\text {th }}, 2013$; accepted July $8^{\text {th }}, 2013$

Copyright (C) 2013 Stanley Jones et al. This is an open access article distributed under the Creative Commons Attribution License, which permits unrestricted use, distribution, and reproduction in any medium, provided the original work is properly cited.

\begin{abstract}
Normal variants of lower limb development such as in-toeing, out-toeing, flat feet, bow-legs and knock knees are a common cause for parental concern and also a common source of referral to pediatric clinics. A thorough history and clinical examination is usually all that is required to make the diagnosis of a normal variant. They also help to exclude pathological conditions that may present in a similar fashion. Radiological and other investigations are not routinely required in children with normal variants of the lower limb except to exclude pathological conditions. Shoe inserts, orthoses and physical therapy are not to be encouraged as they provide no benefit. In the majority of cases the natural history is one of spontaneous resolution of the deformity. Surgery may, however, be required in a small number of patients greater than eight years in whom severe in or out-toeing is present. Parental education and reassurance is an important part of the treatment and must be re-emphasized.
\end{abstract}

Keywords: Normal Variants; Pediatric Orthopedics

\section{Introduction}

Normal variants of lower limb development such as in toeing, out toeing, flat feet, genu varum (bow legs), genu valgum (knock knees) are a common source of parental concern and hence these children are commonly referred to pediatric or pediatric orthopedic clinics [1]. Malony et al. reported that half of all new referrals to their pediatric orthopedic clinic were children with normal variants of lower limb development [1]. This places undue pressure on the resources of these clinics.

It is essential that all clinicians who treat children are able to confidently differentiate children with pathological conditions from those with normal variants [2]. A thorough history and a full clinical examination are usually all that are required to do so.

In addition to the presenting complaint, important aspects of the history that should be sought are $[2,3]$ :

- Ante and perinatal history

- Developmental milestones

- Family history

Clinical examination should focus not only on the presenting complaint but on the child as a whole. The following features suggest a pathological condition and not a normal variant [4].

- Abnormal facies
- Abnormal height

- Asymmetry of limb findings

- Limitation of joint movements

- Leg length discrepancy/hypoplasia

Radiological and other investigations are not routinely required in children with normal variants of the lower limb except to exclude a pathological process.

Once recognized, a child with a normal variant does not require regular review as it is the practice in some clinics. Regular review is detrimental as it serves to reinforce that the child with a normal variant has an abnormality.

The natural history of the majority of normal variants is spontaneous resolution of the respective deformities hence no treatment is required [5]. It is however of utmost importance that the treating clinician reassures and educates the families of these children.

This review serves to highlight the clinical features of the normal variants of the lower limb. It also aids the diagnostic process and informs clinicians about the treatment options emphasizing the importance of reassurance and parental education (Table 1).

\section{In Toeing}

In toeing or an inward pointing foot is more common than out toeing and occurs in nearly 2 out of 1000 
Table 1. Normal variants of the lower limb.

\begin{tabular}{|c|c|c|c|c|}
\hline & $\begin{array}{l}\text { Age of } \\
\text { presentation }\end{array}$ & Sex & Cardinal clinical signs & Management \\
\hline $\begin{array}{l}\text { In toeing } \\
\text { Metatarsus } \\
\text { adductus }\end{array}$ & $1^{\text {st }}$ year & Males & Heel bisector line & $\begin{array}{l}\text { Most cases resolve spontaneously however severe deformities } \\
\text { may require serial casting/surgery }\end{array}$ \\
\hline $\begin{array}{l}\text { Internal tibial } \\
\text { torsion }\end{array}$ & 2 - 4 years & $\begin{array}{l}\text { Males and } \\
\text { females }\end{array}$ & Abnormal thigh foot angle & Resolves in the majority though corrective tibial or femoral \\
\hline $\begin{array}{c}\text { Femoral } \\
\text { anteversion }\end{array}$ & 4 - 7 years & Females & $\begin{array}{l}\text { W sign and squinting } \\
\text { patellae }\end{array}$ & $\begin{array}{c}\text { osteotomies may be required if the deformity is persistent after } 8 \\
\text { years of age }\end{array}$ \\
\hline Out toeing & All ages & $\begin{array}{l}\text { Males and } \\
\text { females }\end{array}$ & $\begin{array}{l}\text { "Charlie Chaplin” } \\
\text { appearance }\end{array}$ & $\begin{array}{c}\text { May not resolve and corrective osteotomies required around } 10 \\
\text { years of age }\end{array}$ \\
\hline Flat feet & All ages & $\begin{array}{l}\text { Males and } \\
\text { females }\end{array}$ & $\begin{array}{l}\text { Absent medial arch on } \\
\text { standing } \\
\text { Arch reconstitutes on tip } \\
\text { toeing }\end{array}$ & $\begin{array}{c}\text { Parental reassurance } \\
\text { Insoles or modified foot wear are not beneficial }\end{array}$ \\
\hline Bow legs & Up to 2 years & $\begin{array}{l}\text { Males and } \\
\text { females }\end{array}$ & $\begin{array}{l}\text { Increased intercondylar } \\
\text { distance }\end{array}$ & Usually resolve by 4 years of age without any intervention \\
\hline Knock knees & $\begin{array}{l}\text { Beyond } 2 \\
\text { years }\end{array}$ & Females & $\begin{array}{l}\text { Increased intermalleolar } \\
\text { distance }\end{array}$ & $\begin{array}{l}\text { Surgery may be required if the deformity fails to resolve } \\
\text { spontaneously }\end{array}$ \\
\hline
\end{tabular}

children [6,7]. It is usually bilateral and observed in boys and girls equally.

The cause of in toeing varies with the age of the child. During the first year of life it is usually the result of metatarsus adductus. In toddlers it may be the result of internal tibial torsion or in combination with metatarsus adductus. In early childhood femoral anteversion is the most common cause. The typical presentation is a history of in toeing when walking and frequent falls.

In addition to a full general examination of the child an assessment of the rotational profile (described by Staheli) should be carried out [8]. The components of the rotational profile include internal and external hip rotation, thigh-foot angle, transmalleolar axis and the foot progression angle (Figure 1).

\subsection{Femoral Anteversion (Increased Femoral Internal Rotation)}

Femoral anteversion is usually observed in early childhood and is most severe between the ages of 4 and 7 years [9]. It is thought to be familial and the presentation is usually bilateral. Girls are more commonly affected.

When standing or walking the patellae are observed to point inwards (squinting patellae) (Figure 2). These children are observed to sit in the typical W position (Figure 3 ).

Rotation of the femur is best assessed with the child lying prone on a couch with the knees flexed to about 90 degrees. Infants have an average of 40 degrees of internal rotation and 70 degrees of external rotation. By 10 years of age internal rotation averages 50 degrees whilst external rotation is about 45 degrees. Internal rotation greater than 70 degrees in association with reduced external rotation is considered significant [10]. Femoral anteversion is considered mild if femoral internal rotation is between 70 to 80 degrees, moderate if it is between 80 to 90 degrees and severe if it is greater than 90 degrees [11].

Radiological investigations are not required to diagnose femoral anteversion.

The natural history is improvement over time hence parental education and re-assurance is of utmost importance.

Orthotics and shoe modification have been shown to have no beneficial effect and should be actively discouraged.

Surgery is occasionally required in children over 8 years of age if the deformity has not improved and causes functional disability. This involves a femoral derotation osteotomy and is usually undertaken at the level of the lesser trochanter.

\subsection{Internal Tibial Torsion or Tibial Intorsion}

This is the commonest cause of an in toeing gait and is usually seen in children between the ages of two to four years though it may be observed in older children. It is usually bilateral though on occasions the parents may state that only one side is affected.

The presenting complaint is one of frequent falls and clumsiness.

Clinical examination involves assessment of the thighfoot angle and the transmalleolar axis. This assessment is again undertaken with the child in the prone position and the knee flexed to 90 degrees (Staheli method). The angle between the long axis of the foot and the axis of the thigh denotes the thigh-foot angle. The normal thigh- 

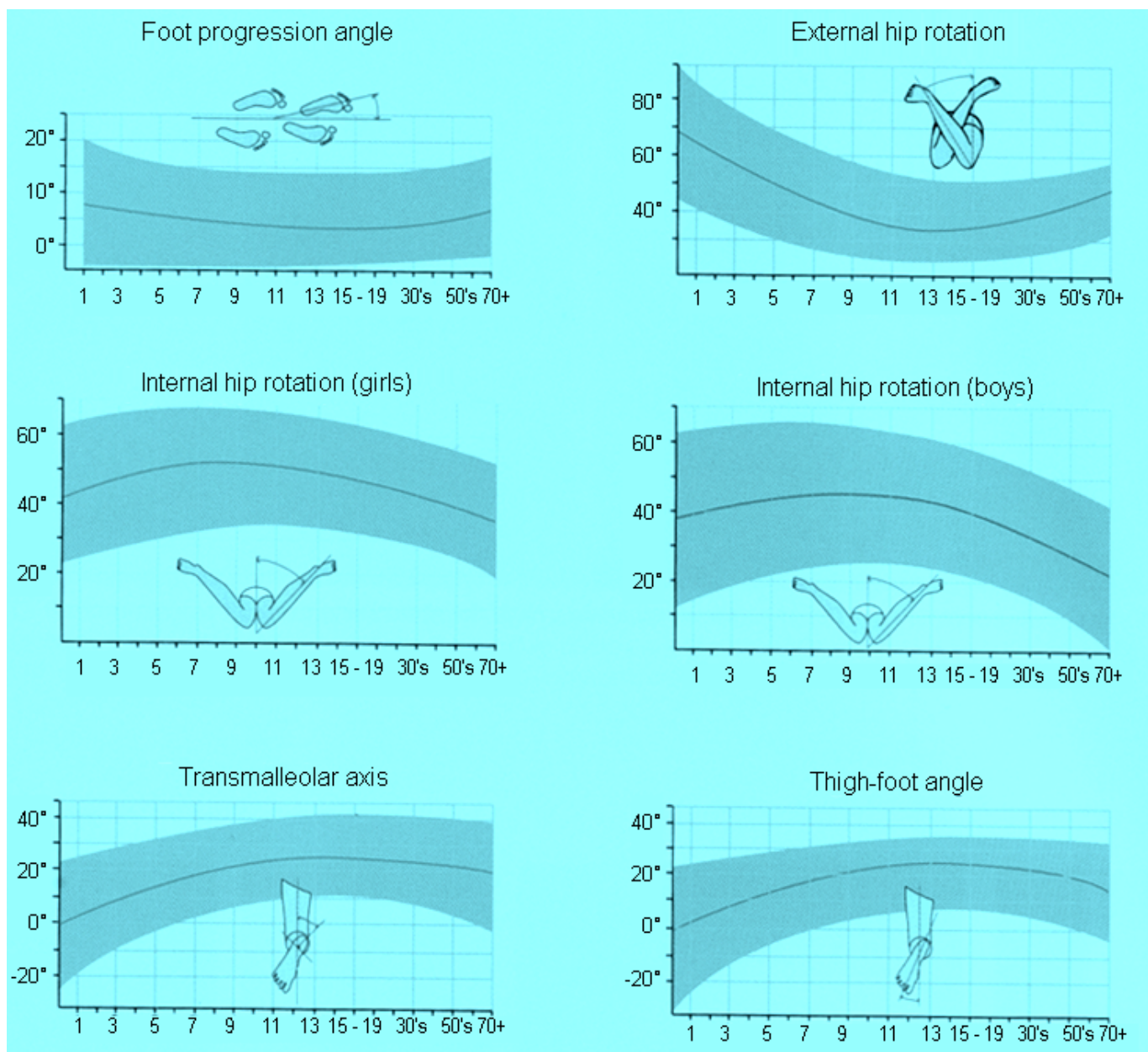

Figure 1. Staheli's rotational profile.

foot angle is 10 to 15 degrees of external rotation and may be up to 30 degrees in a young child $[8,11]$.

Radiographic examination is usually not required except in situations when the deformity is progressive as it is necessary to exclude pathological causes such as rickets, Blount's disease or other skeletal dysplasia.

Normal childhood development is for the tibia to rotate externally and in $90 \%$ of cases internal tibial torsion resolves by the time the child is 8 years old [12].

Braces, shoe modification or orthotic devices do not alter the natural history of internal tibial torsion and are not advisable.

Surgery for internal tibial torsion is rarely indicated. It may be required in children older than 8 years old with a thigh-foot angle greater than 15 degrees internal rotation who have severe functional disability. A supramalleolar osteotomy is the preferred option.

\subsection{Metatarsus Adductus}

This condition refers to medial deviation of the forefoot relative to a normal hindfoot.
It is the most common pediatric foot problem and is observed in 1:5000 live births and 1:20 siblings of patients with metatarsus adductus. It is more common in males, twin births and preterm babies. The exact cause is unknown though various theories have been proposed [13].

Metatarsus adductus is usually observed in the first year of life and though bilateral tends to be more noticeable on the left side. The reason is not clear.

Presenting complaints include abnormal shape of the foot, an in toeing gait and excessive shoe wear.

On clinical examination the foot appears C-shaped with a convex lateral border and a concave medial border.

In the child lying prone with the knee flexed to 90 degrees, an imaginary line drawn to bisect the heel normally goes through the $2^{\text {nd }}$ toe. (Figure 4) In metatarsus adductus this line appears more lateral than the $2^{\text {nd }}$ toe. Bleck has classified this deformity into mild, moderate and severe based on the position of the heel bisector line [14]. The range of motion of the ankle and sub-talar joints is usually normal. 


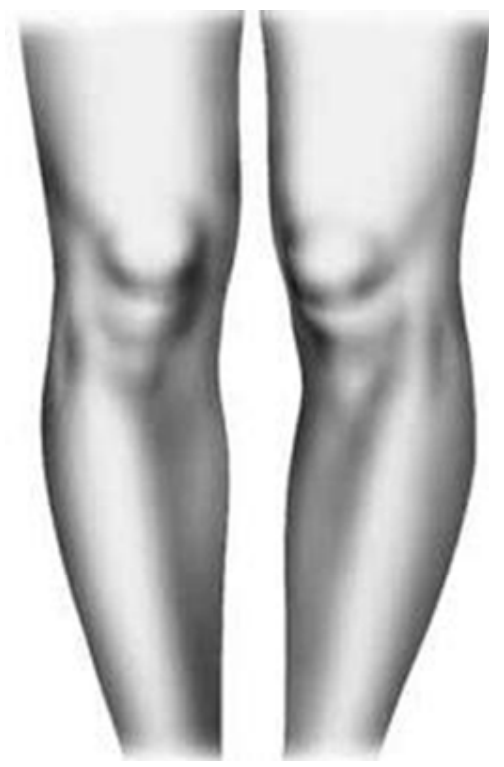

Figure 2. Squinting patellae.

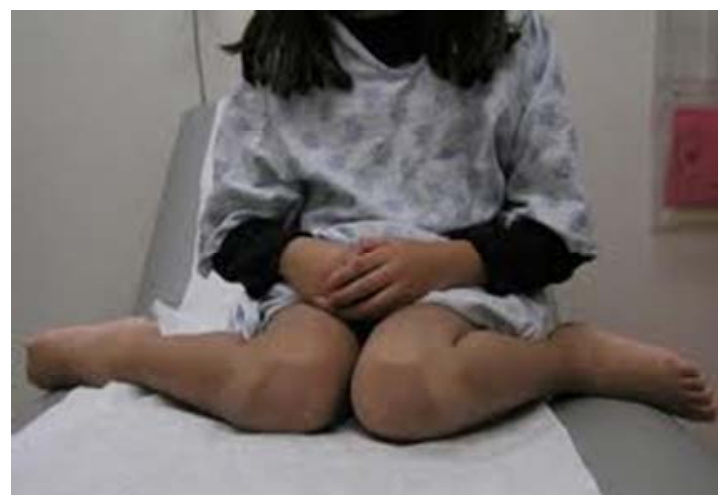

Figure 3. W position.
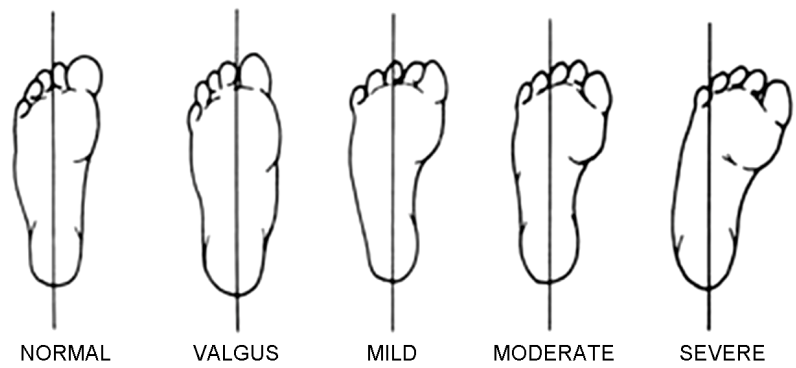

Figure 4. Bleck's heel bisector line.

$85 \%$ to $90 \%$ of the deformities identified at birth resolve without treatment by the time the child is one year old. The more severe deformities or those that fail to resolve require treatment in the form of gentle manipulation and serial casting [15]. Cases resistant to serial casting may require surgery and the options include release of the abductor hallucis tendon, medial mid-foot/tarsometatarsal joint capsulotomy or osteotomy of the medial cuneiform and cuboid in the older child [16].

\section{Out Toeing}

Out toeing is less common than in toeing and its causes are opposite i.e. femoral retroversion or external tibial torsion. It may be associated with flat feet.

Femoral retroversion is common in early infancy and is thought to be due to intra-uterine packaging. It is also observed commonly in obese children [17].

The clinical findings are reversed. In the pre-walking child the feet are usually observed to be rotated outward by about 90 degrees (called Charlie Chaplin appearance).

In the older child (greater than 8 years) with femoral retroversion it is essential to exclude slipped upper femoral epiphysis (SUFE) by undertaking radiographs of the pelvis and hip joints.

External tibial torsion is usually observed between 4 and 7 years of age. The thigh-foot angle is greater than +30 degrees.

The initial treatment is reassurance and parental education. External tibial torsion may not resolve as the child grows and surgery in the form of a tibial osteotomy may be required. This is usually undertaken in the older child around 10 years of age.

\section{Flat Foot}

Flat foot is a foot with loss of the medial longitudinal arch and a large contact area on weight bearing.

Flexible flat feet often run in families and are thought to be more common in those children who wear shoes, are obese or have generalized ligamentous laxity. It is present in nearly all infants and many children (Figure 5).

In the preschool child, the longitudinal arch is usually obscured by plantar fat. As the child grows the plantar fat resorbs, muscles develop and joint laxity reduces leading to the formation of the medial arch.

Children with flexible flat feet are usually asymptomatic. They are however brought by their parents because of concerns about the shape of the feet and the long term consequences.

Clinical examination reveals loss of the medial arch on weight bearing. On tip-toeing the medial arch is observed to be present. In addition the heel valgus corrects to neutral or varus (Figure 6). Movements of the subtalar joint are not limited. Features of generalized ligamentous laxity may be present.

In the adolescent flat feet it is important to exclude pathological conditions such as tarsal coalition. Limitation of movement of the subtalar joint and failure of restoration of the medial arch on tip toeing are clinical features suggestive of tarsal coalition.

Radiological investigations are necessary and x-rays of the feet (oblique views) will reveal a calcaneo-navicular coalition whilst CT scans are required to diagnose a 


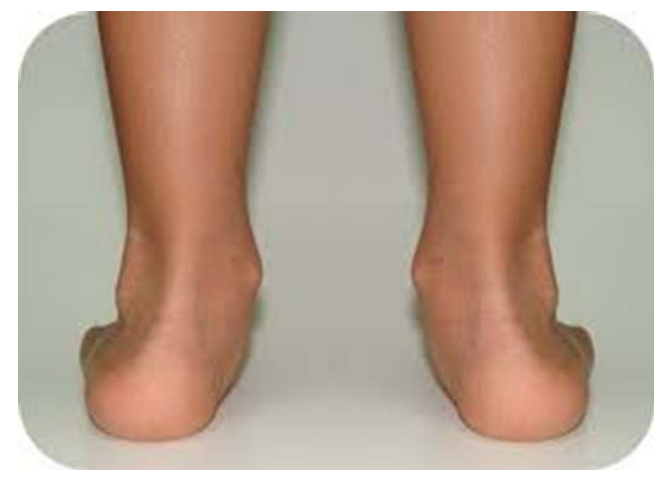

Figure 5. Pes planus.

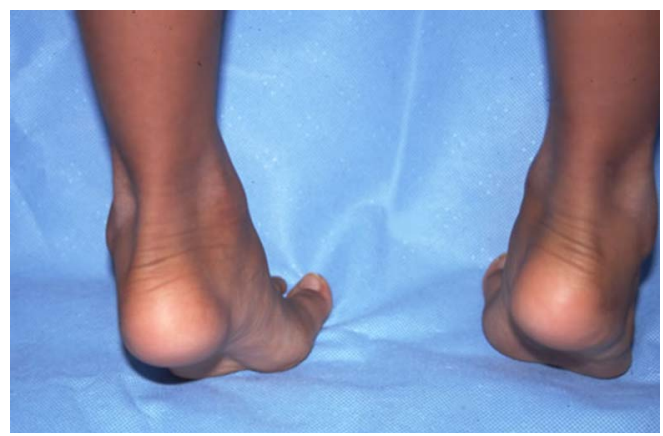

Figure 6. Tip toeing.

talo-calcaneal coalition.

Most children with physiological or flexible flat feet will develop an arch in the first decade of life, though approximately $20 \%$ of individuals will never develop an arch.

The treatment of asymptomatic flexible flat feet using orthotics, insoles or modified shoes has been shown to be ineffective and hence not recommended [18].

\section{Bow-Legs (Genu Varum)}

Symmetrical bowing of the lower limbs up to the age of 2 years is usually physiological (Figure 7). A valgus attitude of the lower limbs develops from 2 to 4 years of age. This reverts to the normal adult alignment at $6-8$ years of age.

On clinical examination abnormal height, abnormal body proportions, asymmetrical deformity, leg length discrepancy, limitation of joint movement are all findings suggestive of a pathological process.

Measurement of the standing inter-condylar distance with the feet placed together is advisable and a distance of up to $6 \mathrm{~cm}$ is considered normal.

Photographs of the lower limbs taken whilst the child is standing helps compare changes over time Radiographic examination is not required except when pathology is suspected.

Physiological bowing usually corrects spontaneously before 4 years of age. Parental reassurance is of utmost importance and treatment using insoles and braces is not required.

Failure of the deformity to correct as expected suggests it is pathological thus necessitating further investigations in the form of radiographs and blood tests i.e. serum calcium, alkaline phosphatase and phosphate.

\section{Knock-Knees}

Genu valgum (Figure 8) is common in the growing toddler as genu varum corrects to genu valgum and then to normal adult valgus alignment (Figure 9) [19]. It is also common in the obese child.

The intermalleolar distance is measured with the child standing and the knees approximated. A distance of up to $8 \mathrm{~cm}$ is considered physiological [20]. Parental reassure-

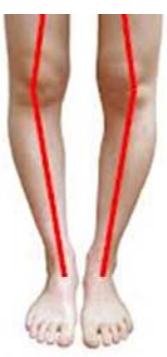

Figure 7. Bow legs or genu varum.

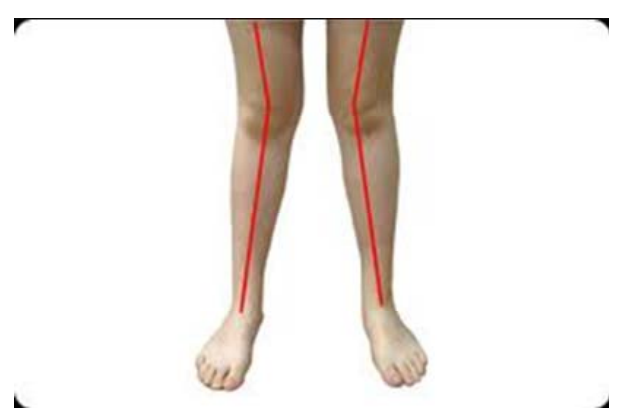

Figure 8. Knock knees or genu valgum.

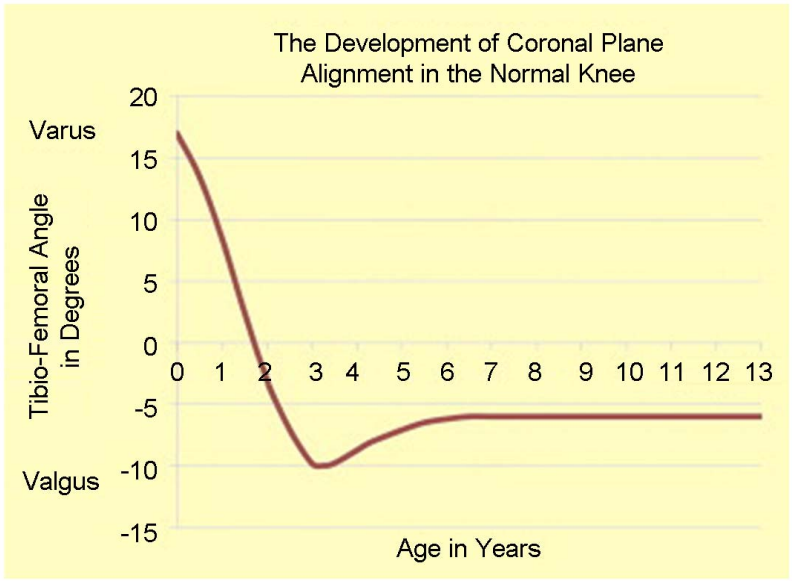

Figure 9. Salinius graph. 
ance is required if the deformity is considered to be physiological.

Progressive deformity in the older child warrants investigations such as radiographs to exclude underlying pathology. The radiographs are also useful in monitoring progression of the deformity. Surgery may be required if the deformity continues to progress.

The surgical options in the skeletally immature child include the guided growth technique using 8 plates or corrective osteotomies.

\section{Conclusion}

Reassurance and parental education is of utmost importance when treating young children with normal variants of the lower limb. This is to be re-emphasized to parents who insist that their children with normal variants require treatment.

Shoe inserts and modifications and orthotics are of no benefit and should be discouraged.

Surgery may occasionally be required in the older child greater than 8 years with in toeing and out toeing.

\section{Acknowledgements}

We would like to thank Liptis Pharmaceuticals Middle east for the financial support to publish this article.

\section{REFERENCES}

[1] D. Molony, G. Hefferman, et al., "Normal Variants in the Pediatric Orthopedic Population," Irish Medical Journal, Vol. 99, No. 1, 2006, pp. 13-14.

[2] T. L. Lincoln and P. W. Suen, "Common Rotational Variations in Children," Journal of the American Academy of Orthopaedic Surgeons, Vol. 11, No. 5, 2003, pp. 312320.

[3] L. T. Staheli, "Lower Limb-Fundamentals of Pediatric Orthopedics," 4th Edition, Lippincott Williams and Wilkins, Philadelphia, 2008.

[4] D. H. Jones and R. A. Hill, "Children's Orthopedics: Normal Development and Developmental Disorders,” R. C. G. Russell, C. J. K. Bulstrode and N. S. Willams, Eds., Bailey and Love's Short Practice of Surgery, 23rd Edition, Hodder Arnold, London, 2000, p. 421.

[5] D. R. Wenger, D. Mauldin, G. Speck, et al., "Corrective Shoes and Inserts as Treatment for Flexible Flatfoot in Infants and Children," The Journal of Bone and Joint Surgery, Vol. 71, No. 6, 1989, pp. 800-810.

[6] A. Dietz, "Intoeing: Fact, Fiction and Opinion," American Family Physician, Vol. 50, No. 6, 1994, pp. 1249-1259, 1262-1264.
[7] L. A. Karol, "Rotational Deformities in the Lower Extremities," Current Opinion in Pediatrics, Vol. 9, No. 1, 1997, pp. 77-80. doi:10.1097/00008480-199702000-00016

[8] L. T. Staheli and G. M. Engel, "Tibial Torsion: A Method of Assessment and a Survey of Normal Children," Clinical Orthopaedics, Vol. 86, 1972, pp. 183-186. doi:10.1097/00003086-197207000-00028

[9] S. B. Murphy, S. R. Simon and P. K. Kejewski, "Femoral Anteversion," The Journal of Bone and Joint Surgery, Vol. 69, No. 8, 1987, pp. 1169-1176.

[10] L. T. Staheli, "Rotational Problems in Children," The Journal of Bone and Joint Surgery, Vol. 75, No. 6, 1993, pp. 939-949.

[11] L. T. Staheli, M. Corbett, C. Wyss, et al., "Lower Extremity Rotational Problems in Children: Normal Values to Guide Management," The Journal of Bone and Joint Surgery, Vol. 67, No. 1, 1985, pp. 39-47.

[12] J. A. Herring, “Tachdjians Pediatric Orthopedics,” 3rd Edition, Vol. 2, WB Saunders, Philadelphia, 2002.

[13] U. A. Hunziker, R. H. Largo, et al., "Neonatal Metatarsus Adductus, Joint Mobility, Axis and Rotation of the Lower Extremity in Preterm and Term Children 0 - 5 Years of Age,” European Journal of Pediatrics, Vol. 148, No.1, 1988, pp. 19-23. doi:10.1007/BF00441806

[14] E. E. Bleck, "Metatarsus Adductus: Classification and Relationship to Outcomes of Treatment," Journal of Pediatric Orthopaedics, Vol. 3, No. 1, 1983, pp. 2-9. doi:10.1097/01241398-198302000-00002

[15] K. Katz, R. David and M. Soudry, "Below-Knee Plaster Cast for the Treatment of Metatarsus Adductus,” Journal of Pediatric Orthopaedics, Vol. 19, No. 1, 1999, pp. 4950. doi:10.1097/01241398-199901000-00011

[16] D. R. Wenger and J. Leach, "Foot Deformities in Infants and Children," Pediatric Clinics of North America, Vol. 33, No. 6, 1986, pp. 1411-1427.

[17] E. J. Wall, "Practical Primary Pediatric Orthopaedics," Nursing Clinics of North America, Vol. 35, No. 1, 2000, pp. 95-113.

[18] L. T. Staheli and L. Giffin, "Corrective Shoes for Children: A Survey of Current Practice,” Pediatrics, Vol. 65, No. 1, 1980, pp. 13-17.

[19] P. Salinius and E. Vankka, "The Development of the Tibiofemoral Angle in Children,” The Journal of Bone and Joint Surgery, Vol. 57, No. 2, 1975, pp. 259-261.

[20] C. H. Heath and L. T. Staheli, "Normal Limits of Knee Angle in White Children: Genu Varum and Genu Valgum,” Journal of Pediatric Orthopaedics, Vol. 13, No. 2, 1993, pp. 259-262. 